\title{
Rural Livelihood Resilience: An Assessment of Social, Economic, Environment, and Physical Dimensions
}

\author{
Iwan Rudiarto ${ }^{1}{ }^{*}$, Wiwandari Handayani ${ }^{1}$, Holi B. Wijaya ${ }^{1}$, and Tia D. Insani ${ }^{1}$ \\ ${ }^{1}$ Department of Urban and Regional Planning, Diponegoro University, Semarang, Indonesia
}

\begin{abstract}
Rural coastal area in northern part of Sayung subdistrict is prone to tidal flood as effect of abrasion and sea level rise. This study looks at the condition of five villages that suffer the most tidal flood there and tries to measure the livelihood resilience of the people through household survey. Livelihood Resilience Index (LRI) and Resilience Radar are adapted to calculate the score and level of livelihood resilience. Four dimensions (social dimension, economic dimension, environment dimension, and physical-infrastructure dimension) are used to express the livelihood resilience score of each study area. Sriwulan village has the highest score among the study areas and it has medium level of livelihood resilience while Timbulsloko village which has the lowest score becomes the only study area with low level livelihood resilience. However, this result in score and level categorization are only an attempt to describe the spectrum of livelihood resilience instead of intending to provide a set of classification. It hopefully can help to identify what can be started first in the work of building resilience of the people and community in tidal floodprone areas.
\end{abstract}

\section{Introduction}

Coastal area is dynamic and prone to environmental change including sea level rise caused by climate change $[1,2]$. It is projected that by 2100 , Indonesia's sea level would rise up by $1.1 \mathrm{~m}$ as in 20 century alone the sea level rise has already increased by $10-25 \mathrm{~cm}$. The impact of sea level rise can be seen where it creates a tidal flood risk in coastal areas [3]. Tidal flood is threatening people living in coastal areas as it does not only disrupt their living environment but it also brings issues for their socio-economic activities. Coastal communities generally have a high dependency on the coastal ecosystem to support their livelihood. The livelihoods of coastal resource-dependent communities are strongly linked to the well-being of coastal and marine ecosystems [4]. Similarly, Bailey and Pomeroy [5] in the context of coastal regions of Asia have argued that 'fishing communities are best understood as dependent not on a single resource but on a whole ecosystem. This expanded understanding of tropical coastal resources is the key to stability for households and communities in South East Asia's coastal zones'.

\footnotetext{
* Corresponding author: irudiarto@yahoo.com
} 
Household stability has many influence factors with livelihood to be one of it. Livelihood can be seen simply as a means of human beings in meeting their basic needs to sustain a living. A livelihood consists of the capabilities, assets, and activities that are required for a means of living [6]. Chamber and Conway also offers a concept of sustainable rural livelihood as one which can cope with and recover from stress and shocks, maintain or enhance its capabilities and assets, and provide sustainable livelihood opportunities for the next generation; while also contributes benefits to other livelihoods at various levels in the short and long term [6]. This concept is closely related to livelihood resilience as conceptualized by Tanner [7]: 'the capacity of all people across generations to sustain and improve their livelihood opportunities and well-being despite environmental, economic, social, and political disturbances'. While livelihood sustainability means to keep the functioning system going, livelihood resilience emphasizes the ability of the system to bounce back after disturbances such as environmental disasters.

In Central Java, most of the climate-related disasters were found in rural areas with $80 \%$ of tidal flood events occur in areas located less than $5 \mathrm{~km}$ from the coastline [8]. Coastal area in Demak Regency, Central Java Province has been experiencing tidal flood as an impact of sea level rise and land subsidence since mid-1990. The tidal flood has made people lose their houses and lands. A lot of rice fields and fishponds that were previously the main source of their living are now gone under seawater. Based on socio-economic measures and the occurrence of climate disaster events, villages in coastal areas of Sayung sub-district were categorized as most vulnerable. They were exposed by tidal flood or both tidal flood and general flood with a quarter to half of the population were working in farming and fishery [9]. Those whose livelihood depended on the availability of coastal resources affected directly by the climate disaster events.

Drawing upon Resilience Radar by Bolte et al. [10] and Livelihood Resilience Index (LRI) by Weldegabriel and Amphune [11], this study tries to measure the livelihood resilience of the people living in Sayung subdistrict which affected by a long-term tidal flood. the result on this initial measurement can give a picture into the spectrum of conditions that presents in the rural livelihood system when faced with tidal flood. The findings of this study can be used to further build reliable tool in measuring the level of livelihood resilience in rural coastal community as to this day, there is still not any standardized tools for it yet.

\section{Data and Method}

\subsection{Study area}

Sayung sub-district in Demak Regency is located on 0 - 3 meters above sea level (asl) and among areas in northern Java that suffer from severe abrasion and tidal flood. For this study, the study is focused on the five forefront northern villages in Sayung sub-district adjacent to coastal line of Java Sea. Those five villages are Sriwulan, Bedono, Timbulsloko, Surodadi, and Banjarsari. They are frequently affected by tidal flood. Large area in villages like Bedono village and Timbulsloko village have been disappeared because of tidal flood while houses in Sriwulan village have been destroyed by high tidal flood last December.

\subsection{Data needs}

Data used for this study were based on the socioeconomic characteristics including material and social resources, and routine activities as components people need to be able to live. These data were obtained from randomly selected families in the study areas. Standardized 
questionnaires were handed out to a total of 35 families from 5 forefront villages, the nearest ones to coastal line, in Sayung sub-district. Distribution of the questionnaire for the five villages was proportioned to each of their population. Socioeconomic data that are being captured were related to their livelihood as well as relevant questions on how tidal flood related to their social and economic activities. The time frame used in the questionnaire questions was to documented and measured condition happened between mid-2017 to mid-2018 with the exception on some periodic questions that asked for conditions as far as ten years back from mid-2018.

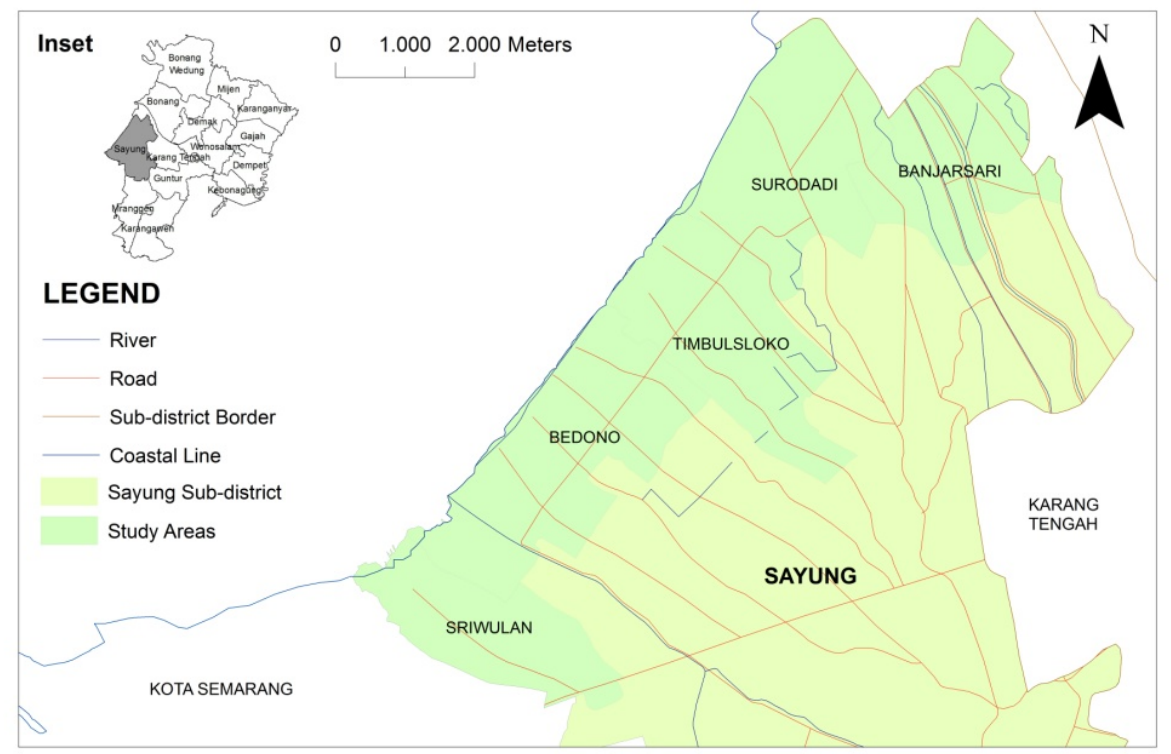

Fig. 1. Map of Study Areas

\subsection{Method}

Resilience is known as a multidimensional concept that combines relevant evidence on how people withstand shocks [11]. Common understanding on the resilience shows that it can be possibly achieved upon building three interrelated capacities (adaptive, absorptive, and transformative), which are relevant to its measurement [11]. Previous studies have tried to measure resilience by building a composite index. In trying to measure the livelihood resilience of people in coastal villages of Sayung sub-district, this study is combining Livelihood Resilience Index (LRI) by Weldegabriel and Amphune [11] and Resilience Radar by Bolte et al. [10] to build a simple composite index. LRI was conceptualized from some approaches such as Livelihood Vulnerability Index (LVI) by Hahn et al. [12], Sustainable Livelihood Framework by DFID [13], and Resilience Index Measurement and Analysis (RIMA) by FAO [14]. It was then expressed in quotation 1.

$$
\begin{gathered}
\mathrm{LRI}_{\mathrm{n}}=\mathrm{f}\left(\mathrm{AC}_{\mathrm{n}}, \mathrm{ABC}_{\mathrm{n}}, \mathrm{TC}_{\mathrm{n}}\right) \\
\mathrm{LR}_{\text {Sayung }}=\mathrm{f}\left(\mathrm{Soc}_{\text {Sayung }}, \mathrm{Eco}_{\text {Sayung }}, \mathrm{Env}_{\text {Sayung }}, \mathrm{Inf}_{\text {Sayung }}\right)
\end{gathered}
$$

$\mathrm{LRI}_{n}$ is the resilience index for household $\mathrm{n}$ with $\mathrm{AC}_{\mathrm{n}}$ expresses its adaptive capacity, $\mathrm{ABC}_{\mathrm{n}}$ expresses its absorptive capacity, and $\mathrm{TC}_{\mathrm{n}}$ expresses its transformative capacity. 
These components were the results of aggregating some indicators and weighting them equally. AC consists of income and consumption, ownership of assets, natural capital (land), educational status, household size, and social capital. ABC consists of access to credit, diversification of income, and disaster exposure. TC consists of access to services, infrastructure, and access to formal safety nets. Utilizing those set of indicators of LRI [11] and combining it with resilience livelihood component (livelihood diversity, dependency on natural resources, income earner, resilience measures, and food security) in Resilience Radar [10], some indicators were chosen and tailored into questionnaire questions to measure the livelihood resilience in tidal flood-prone villages in Sayung sub-district.

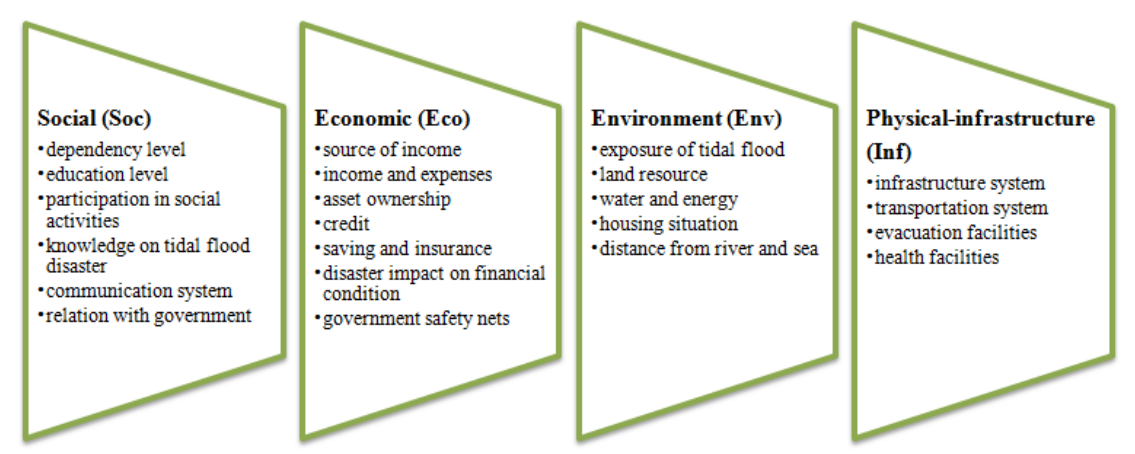

Fig.2. Indicators and dimensions of livelihood resilience

Among many definitions, resilience in the context of climate change is also seen as a concept to build capability on reducing vulnerability [15]. Both resilience and vulnerability have multidimensional natures hence both are often discussed as part of developmentrelated frameworks. Vulnerability is one of indicators in the disaster risk framework which consists of four dimensions: social dimension, economic dimension, environment dimension, and physical dimension [16]. On the other hand, resilience is a stipulating condition of sustainability according to Sustainable Livelihood Framework [17]. Under the framework, resilience is fueled by five capitals that consist of human capital, social capital, natural capital, physical capital, and financial capital [13]. This study tries to see livelihood resilience through dimensions interlinked between the two frameworks which are: social, economic, environment, and physical infrastructure. By identifying how each dimension shapes the level of resilience, works on overcoming the vulnerability could be adjusted to the predictive performance of each dimension. Figure 2 shows the chosen indicators and the dimension they are part of.

Table 1. Interpretation of Livelihood Resilience Level

\begin{tabular}{|c|c|}
\hline Index score & Interpretation of Resilience \\
\hline $0.81-1.00$ & Very high \\
\hline $0.61-0.80$ & High \\
\hline $0.41-0.60$ & Medium \\
\hline $0.21-0.40$ & Low \\
\hline $0.00-0.20$ & Very low \\
\hline
\end{tabular}


Each indicator was translated into questions with some answer choices that will have a score between 0.00 to 1.00 . The highest score of 1.00 for the answer choice with "positive effect" and 0.00 for the answer choice with 'negative effect' in terms of achieving resilience. Questions with a yes or no answer will have 1.00 or 0.00 score while questions with more than 2 answer choices will have a score that represent equal intervals. For instance, questions with four answer choices have values of $0.00,0.33,0.67$ and 1.00 . The scoring system for this study is based on Resilience Radar [10] in order to define the level of livelihood resilience of the study areas. Table 1 shows the interpretation of livelihood resilience level based on the total score of all indicators that are calculated using quotation 2.

\section{Result and Discussion}

Sayung sub-district is one of the areas suffering from abrasion and sea level rise that causes tidal flood to sink a lot of its land especially near the coastal line on its northern part. In the five villages of study areas, livelihood resilience is tried to be examined through four dimensions. In this section, each dimension will be discussed first before going through to the discussion of the overall livelihood resilience level. Information obtained during the questionnaire distributions will also enrich the data presented as the result of scoring calculation.

\subsection{Social dimension}

Indicators of social dimension were measured by giving a score to the answers of respondents from study areas. The closer the aggregate score of each indicator to 1.00 shows stronger condition that will be able to support the household respondents in achieving livelihood resilience. From six indicators of social dimension, indicators with significantly high scores for all study areas come from dependency level and participation in social activities. Dependency level is based on the dependency ratio that shows the financial burden of the productive household members over the unproductive ones. A higher ratio gives more negative effect to livelihood resilience. Therefore in the calculation of the social dimension, dependency level score expresses the opposite condition where the greater score comes from the lower dependency ratio.

Social activities in the study areas range from housewives gathering (arisan), neighborhood monthly meeting, to emergency gathering because of disaster events. This indicator also includes household participation in the social institutions such as farmers group or village cooperative. The high participation shows a potential of dependable bond between participants with the community in their neighborhood. Accordingly, the village whose households have higher participation in social activities will be more likely to cooperate easily when an emergency condition such as disaster event happens. Figure 3 shows the score of six indicators in social dimension from all study areas.

Education level score shows the average education level received by household members of the participants. Its score expresses positive effect hence the higher the score, the more resilience the household could be. Communication system score came from the how the participants communicate with other members in their community in order to work together especially when it comes to their community affairs in the time of crises such as after disaster events. It ideally shows a consistent pattern with participation in social activities but the data shows that it doesn't go that way. It might be despite their high participation in social activities, they don't specifically build a communication routine or 
system that is related to crises or disaster management. This is further supported by the common low score on knowledge on tidal flood disaster.

Generally, the people living in these tidal flood-prone areas are very well aware of the threat and damage that they face. Most of them are survivors that choose to stay and continue to live in the areas despite it sinking slowly. However, this does not guarantee that they have reliable disaster management system that can save them from losses, either in household level or community level. They don't have an early warning system that can alarm them about the tidal flood except for the predictive rising tide schedule that they obtain from the navy office. Most of them only learn naturally about what to do in the face of tidal flood from the years they live with it, they don't have procedural disaster mitigation or adaptation. Their adaptations in tidal flood is only by raising their houses and roads without a long-term financial plan nor strategic plan.

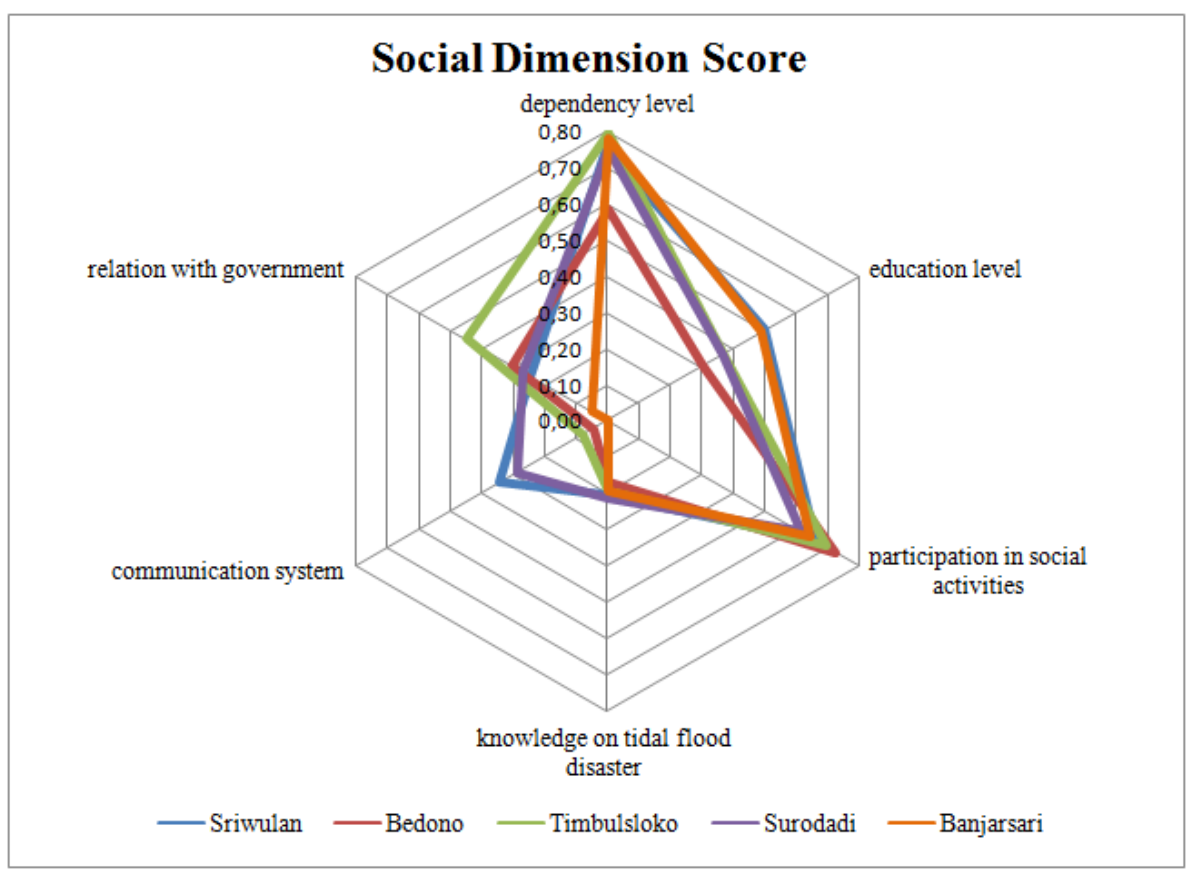

Fig. 3. Graphic of social dimension score

A low score is also shown in all study areas in relation to the government. Communications are built with governments from all levels including institutional level although the people there don't see any significant cooperation and support coming from it. Most government supports come when the disaster happens and it is almost always foods. They are hoping for a sufficient support like special budget for after disaster recovery in their neighborhood moreover that Sayung sub-district is commonly known for its tidal flood disaster and is one under the national development agendas for flood management. However, according to the respondents, they were informed by Badan Penanggulangan Bencana Daerah (BPBD - regional board for disaster management) of Demak Regency that such support cannot be given as according to regulation on disaster, tidal blood does not fall under disaster category. As of now, the people can only hope for an improvement that will come in effect with the development of sea banks along the northern part of Semarang City to Demak Regency. The development is part of toll road development agenda from the national government that will start this year. It is said to help lessen the abrasion and 
control the sea water to come flooding the areas along the coast of Java Sea including Sayung sub-district.

\subsection{Economic dimension}

In the economic dimension, source of income expresses whether the main income source of the households is dependent to natural resources as well as its ecosystem and how many additional income source that support their livelihood. From all study areas, except for Sriwulan, other villages scores are low (see Figure 4). This indicates that most of the people there have the main income that is dependent on natural resources and its ecosystems such as fisherman and fishpond farmer. They mostly depend only on that one source of income or have a single additional income source. Sriwulan shows a medium score because most of all people there have off-farm permanent works as their source of income, therefore, it is more stable and unlikely to be affected by tidal flood.

Most of the household's income is less than 2 million rupiahs per month which half of it are obtained from on-farm economic activities. Because of the severity of tidal flood in the study areas, most households especially in Bedono, Timbulsloko, and Surodadi constantly have to spend for recovery on their assets because of tidal flood. However, the overall expenses of the households are mostly not more than the amount of their income. While asset ownership shows scores on the medium range for study areas except for Sriwulan, which scores on the lower range, scores of credit for all study areas are on the higher range because most households keep themselves for spending more than what they got. For households that depend on on-farm works, the nature of its unpredictability makes them hesitant to have formal credit in the fear of their inability to pay it back timely.

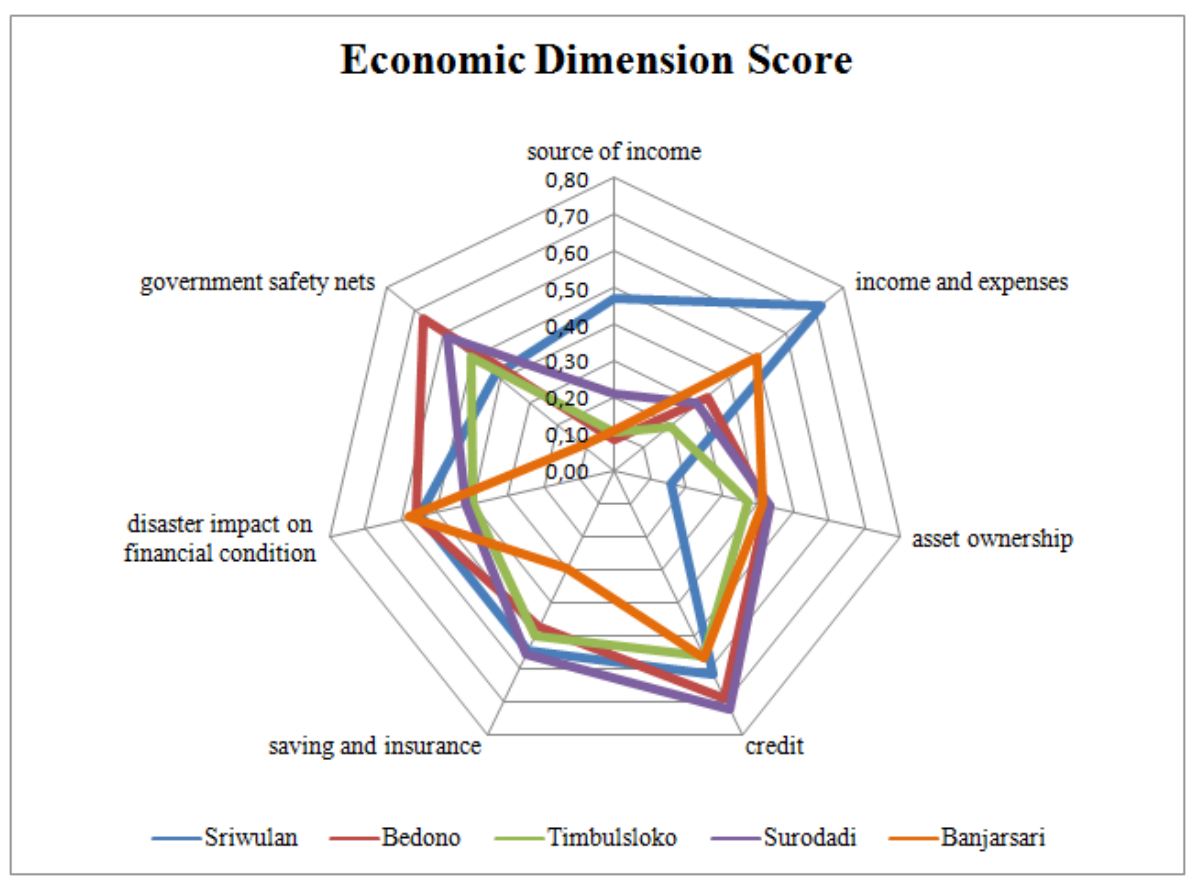

Fig. 4. Graphic of economic dimension score 
Saving and insurance scores for study areas except for Banjarsari that is on lower range, are on the medium range. In the span of a year, the households have the ability to save at least as much as their monthly income. Almost all the respondents already have health insurance that is mostly covered by national health insurance program from Badan Pengelola Jaminan Sosial Kesehatan (BPJS Kesehatan - government institution in charge of social safety net programs) or through the ownership of Kartu Indonesia Sehat (KIS part of government safety nets for the poor). Tidal flood definitely interferes their daily activities but it is not completely impacted their economic productivity hence the scores of disaster impact on financial condition are on the medium range. Government safety nets are available for the poor households and most of the respondents receive raskin (rice ration for the poor) which helps them to meet their daily needs of food.

\subsection{Environment dimension}

Under environment dimension, scores on exposure of tidal flood are on the lower range (see Figure 5) as its severity is so high where the neighborhood of the respondents are always flooded up to $30 \mathrm{~cm}$ high every day. The rising tide that flooded houses and neighborhood usually comes in unpredictable time. It makes evacuation hard to do especially if the high tide comes during late at night or in daytime when people are busy doing their job and daily activities. For land resource indicator, it is related to how the availability and access to land are important for almost all of the household in the study area because most of them are relying on on-farm works for their livelihood. Bedono has the highest score on land resource while other villages of study areas are on the medium range. The higher score shows that the households in the village are less dependent on land productivity for their livelihood.

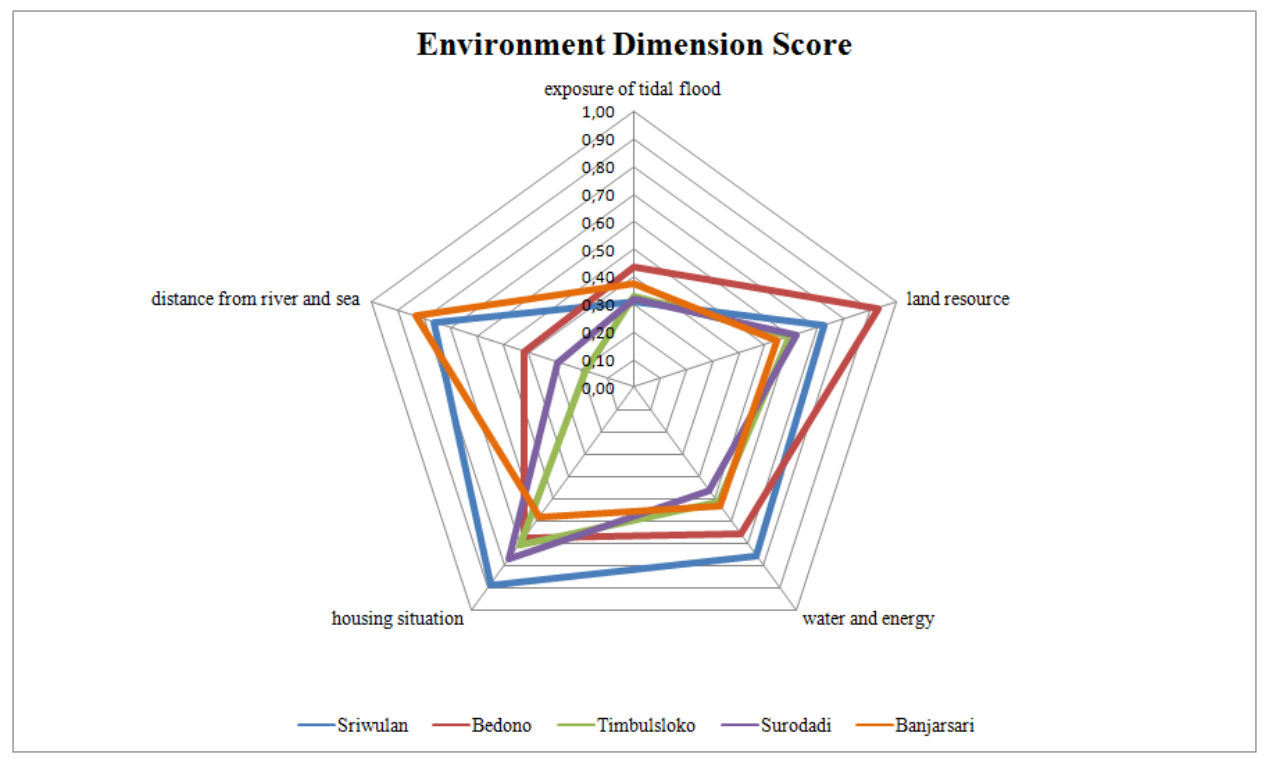

Fig. 5. Graphic of environment dimension score

There are generally little to no problem on the availability and access to clean water and energy hence its indicator scores of all study areas are on the medium range. The housing situation of the households is generally in a good condition in terms of how they are permanently built, provide proper spaces for its household members, and have its own 
lavatory hence the scores are on medium to high range. However, some of the houses have their yards and surrounding areas flooded as can be seen on Figure 6. For the distance of the household's location from river and sea, Sriwulan village and Banjarsari village are in a safer position as indicated by their high scores while the other three villages scores are on the low range with Timbulsloko village scores the lowest.
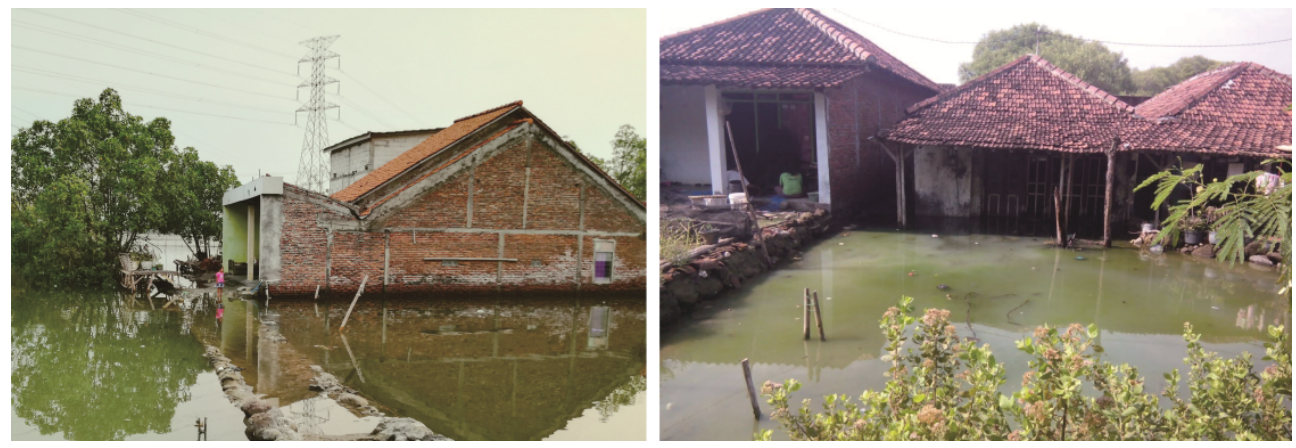

Fig. 6. Impact of tidal flood on housing condition in study areas

\subsection{Physical-infrastructure dimension}

Physical infrastructure is vital in supporting the household's activities as well as in enabling evacuation at the times of disaster events. Tidal floods are flooding most of the access road (see Figure 7) in the study areas and when the tide is high, the access is blocked and vehicles have to go through the flood. Although most of the roads are still functioning, the condition is so poor and give a safety concern for the user. The study areas are not covered by public transportation and they have to rely on their own vehicles in order to travel for their works, other daily activities, or evacuating themselves when the disaster events happen.
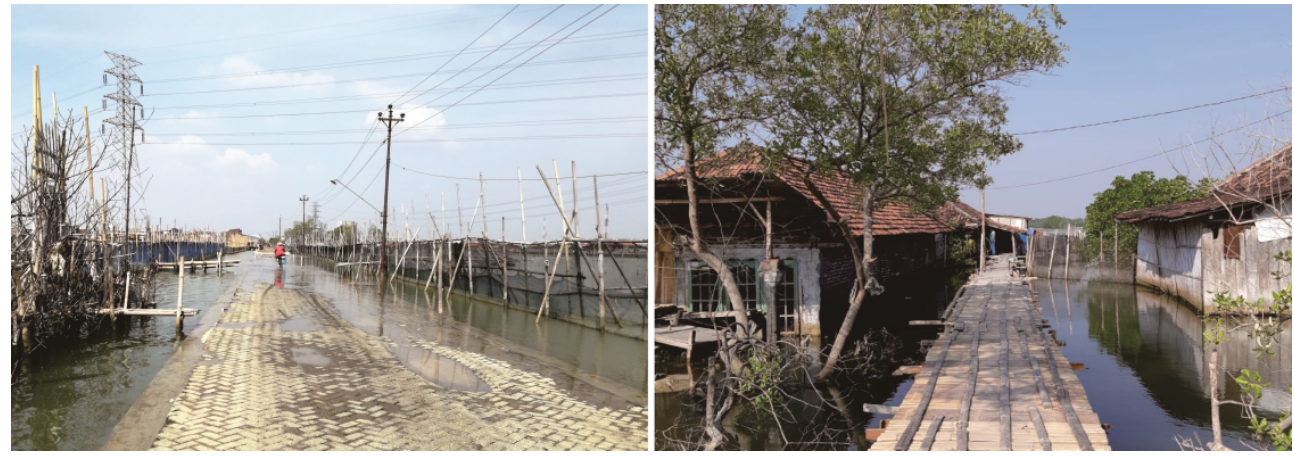

Fig. 7. Main road in Sriwulan village is flooded by tidal flood (left) and an impermanent bridge is built to replace the sinking road in Timbulsloko village (right)

As mentioned on the beginning of the discussion, most of the people in the study areas are choosing to stay and survive the tidal flood in their own houses, hence they don't have evacuation procedure to gather people in a safer place. Even when they need to evacuate, they will just gather on public buildings available such as school, mosque, or balai desa. These buildings are typically short in supporting facilities like lavatory or healthcare room. Therefore, the score for evacuation facilities is on the low range for all study areas. The 
only indicator with a significantly high score is health facilities as it is available, accessible, and located in the area unaffected by tidal flood. Complete scores of all indicators under physical-infrastructure dimension can be seen on Figure 8 below.

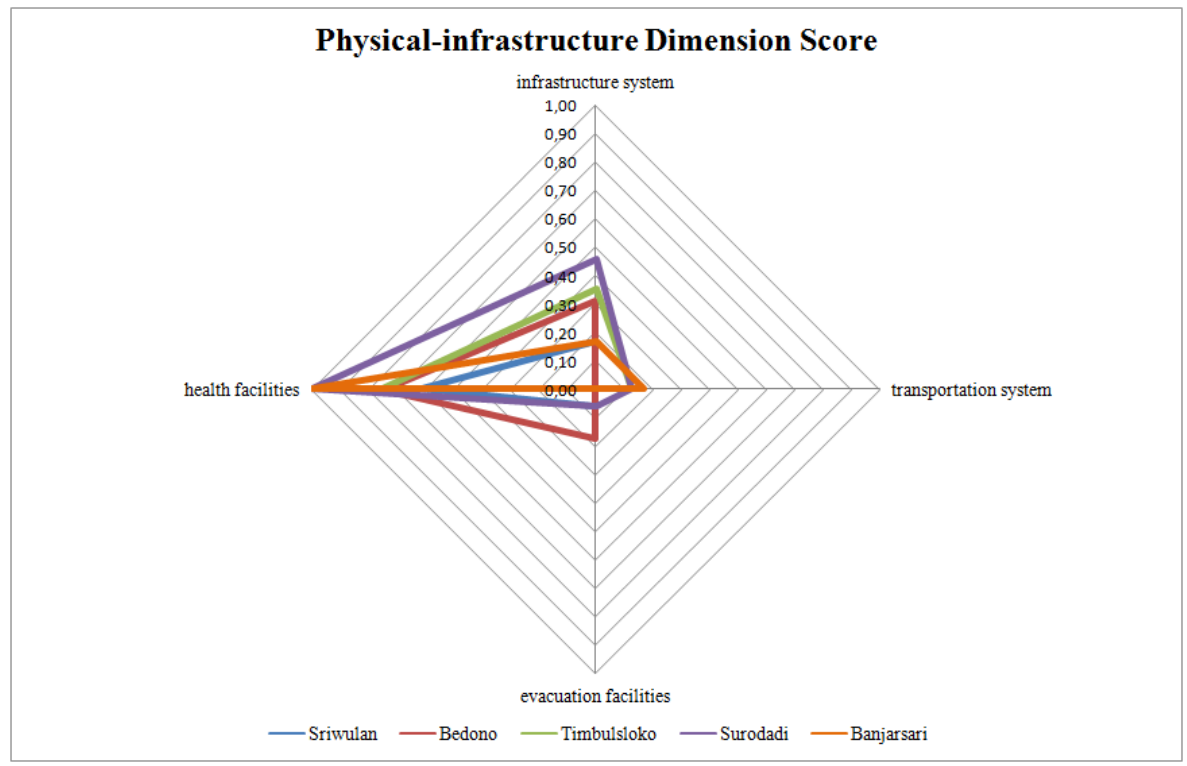

Fig. 8. Graphic of physical-infrastructure dimension score

\subsection{Level of livelihood resilience}

This section will wrap up the discussion with the calculation result of the overall livelihood resilience score from each village. As can be seen in Table 2, the end scores of the study areas do not show a significant gap. Sriwulan got the highest score and Timbulsloko got the lowest. From the five villages of the study areas, four villages have a medium level of livelihood resilience while Timbulsloko is categorized in the low level. Environment dimension has the highest score and thus the biggest share on the total livelihood resilience score followed by economic dimension. It means that these dimensions might be the key points that could be further worked on in order to achieve the higher level of livelihood resilience. In other words, an improvement on the indicators of those dimensions can help the household and neighborhood to be more resilience and adaptive in the face of tidal flood disaster.

Table 2. Livelihood Resilience Score and Level

\begin{tabular}{|c|c|c|c|c|c|}
\hline & Sriwulan & Bedono & Timbulsloko & Surodadi & Banjarsari \\
\hline Social dimension & 0.45 & 0.35 & 0.33 & 0.42 & 0.36 \\
\hline Economic dimension & 0.50 & 0.46 & 0.38 & 0.46 & 0.37 \\
\hline $\begin{array}{c}\text { Environment } \\
\text { dimension }\end{array}$ & 0.69 & 0.62 & 0.47 & 0.49 & 0.57 \\
\hline $\begin{array}{c}\text { Physical- } \\
\text { infrastructure } \\
\text { dimension }\end{array}$ & 0.21 & 0.31 & 0.31 & 0.41 & 0.33 \\
\hline LR Score & 0.46 & 0.44 & 0.37 & 0.45 & 0.41 \\
\hline LR Level & Medium & Medium & Low & Medium & Medium \\
\hline
\end{tabular}




\section{Conclusion}

This study is mainly focused on the coastal northern villages in Sayung sub-district that have suffered from tidal flood for many years. Therefore the livelihood resilience that is tried to measure is specific for the households in those areas. Among the four dimensions used for the scoring, environment dimension and economic dimension shows the highest score and thus the biggest share that make up the overall score of livelihood resilience. It would be likely that the two dimensions are also vital in determining the level of livelihood resilience of the study areas. In this study, Sriwulan becomes the most resilient villages among others despite it only being on medium level and Timbulsloko becomes the only village being in the low level of livelihood resilience. And yet, this result in score and level categorization is only an attempt to describe the spectrum of livelihood resilience instead of intending to provide a set classification. Hopefully, this study can help to identify what can be started first in the work of building resilience of the people and community in tidal flood-prone areas.

\section{Acknowledgment}

This paper is part of the research on "Rural Resilience and Climate Change Impact in the Rural Coastal of Central Java Province, Indonesia" funded by the Directorate of Research and Community Services, Directorate General of Higher Education, Ministry of Research and Technology, Indonesia.

\section{References}

1. Susandi, A., Herlianti, I., Tamamadin, M. \& Nurlela, I. Dampak Perubahan Iklim Terhadap Ketinggian Muka Laut di Wilayah Banjarmasin. J. Ekon. Lingkung. 12, 5-8

2. Sejati, K. Pemanasan Global, Pangan, dan Air (Masalah, Solusi, dan Perubahan Konstelasi Geopolitik Dunia). (Gadjah Mada University Press, 2011).

3. McGranahan, G. \& Balk, D. The rising tide: assessing the risks of climate change and human settlements in low elevation coastal zones. Environ. ... (2007).

4. Ferrol-Schulte, D., Gorris, P., Baitoningsih, W., Adhuri, D. S. \& Ferse, S. C. A. Coastal livelihood vulnerability to marine resource degradation: A review of the Indonesian national coastal and marine policy framework. Mar. Policy 52, 163-171 (2015).

5. Bailey, C. \& Pomeroy, C. Resource dependency and development options in coastal Southeast Asia. Soc. Nat. Resour. 9, 191-199 (1996).

6. Chambers R. and Conway, G. . Sustainable Rural Livelihoods:Practical Concepts for 21st Century. Ids Discuss. Pap. 296, 29 (1991).

7. Tanner, T. et al. Livelihood resilience in the face of climate change. Nat. Clim. Chang. 5, 23-26 (2014).

8. Rudiarto, I., Handayani, W. \& Setyono, J. S. A Regional Perspective on Urbanization and Climate-Related Disasters in the Northern Coastal Region of Central Java, Indonesia. Land 7, 34 (2018).

9. Rudiarto, I., Pamungkas, D., Hajar, A. \& Adam, K. Kerentanan Sosio-Ekonomi terhadap Paparan Bencana Banjir dan Rob di Pedesaan Pesisir Kabupaten Demak. $J$. Wil. dan Lingkung. 4, 153-170 (2016).

10. Bolte, P. et al. Resilience Radar. (2017). 
11. Weldegebriel, Z. B. \& Amphune, B. E. Livelihood resilience in the face of recurring floods: an empirical evidence from Northwest Ethiopia. Geoenvironmental Disasters 4, 10 (2017).

12. Hahn, M. B., Riederer, A. M. \& Foster, S. O. The Livelihood Vulnerability Index: A pragmatic approach to assessing risks from climate variability and change-A case study in Mozambique. Glob. Environ. Chang. 19, 74-88 (2009).

13. DFID. Sustainable Livelihoods Guidance Sheets Vulnerability Context Transforming Structures and Livelihood Strategies Livelihood. Sustain. Livelihoods Guid. Sheets 10 (1999). doi:10.1002/smj

14. FAO. RIMA-II Resilience Index Measurement and Analysis - II. (2016).

15. Cox, R. S. \& Hamlen, M. Community Disaster Resilience and the Rural Resilience Index. Am. Behav. Sci. 59, 220-237 (2015).

16. Bollin, C., Carddenas, C., Hahn, H. \& Vasta, K. S. Natural Disaster Network: Disaster Risk management by Communities and Local Government. (2003).

17. Keating, A. et al. Development and testing of a community flood resilience measurement tool. Nat. Hazards Earth Syst. Sci. 17, 77-101 (2017). 